\title{
Platelet activation in adult HIV-infected patients on antiretroviral therapy: a systematic review and meta-analysis
}

\author{
Bongani B. Nkambule 1* $^{*}$, Vuyolwethu Mxinwa', Zibusiso Mkandla', Tinashe Mutize' ${ }^{1}$ Kabelo Mokgalaboni',
} Tawanda M. Nyambuya' and Phiwayinkosi V. Dludla²

\begin{abstract}
Background: Antiretroviral therapy (ART) alters platelet reactivity, and as a consequence, patients living with HIV may be at an increased risk of cardiovascular disease (CVD). The current evidence on platelet activation levels in patients with HIV remains inconclusive. We therefore aimed to systematically synthesise evidence on the association of platelet activation in HIV-infected patients on successful treatment.

Methods: Electronic databases were searched from inception until November 2019. Studies were included if the primary or secondary outcome of the study was to assess platelet activation in HIV-infected patients on ART. The primary outcome of this review included the levels of platelet activation. The pooled effect estimates were calculated using a random-effects meta-analysis model.

Results: We identified 30 studies comprising of 2325 participants. The pooled estimates showed elevated levels of platelet activation in treatment-naive HIV-infected patients compared to uninfected controls (Hedges' g $2.00[95 \% \mathrm{Cl}$ $1.05,2.94] ; z=4.12, p<0.0001$ ). These remained elevated despite successful ART (Hedges' $g 2.05$ [95\% Cl 0.58, 3.52]; $z=2.71, p=0.0067)$.

Conclusion: The levels of platelet activation are elevated in treatment-naïve HIV-infected patients, and these persist during successful ART. Further studies should assess the clinical relevance of monitoring the levels of platelet activation in HIV-infected patients on ART.
\end{abstract}

Keywords: Platelets, P-selectin, Thrombosis, Cardiovascular disease, Antiretroviral therapy, HIV

\section{Background}

In the era of combination antiretroviral therapy (cART), the overall life span of people living with HIV (PLWHIV) on ART is now almost similar to that of uninfected individuals $[1,2]$. However, disparities in treatment outcomes still exist in low-income and high-income countries [3]. Amongst ARTtreated patients, the most prevalent comorbidities include

\footnotetext{
*Correspondence: nkambuleb@ukzn.ac.za

${ }^{1}$ School of Laboratory Medicine and Medical Sciences (SLMMS), College of Health Sciences, University of KwaZulu-Natal, Private Bag X54001, Durban 4000, South Africa

Full list of author information is available at the end of the article
}

cardiovascular disease (CVD) and hepatic disorders [4]. CVD remain a challenge in the management of PLWHIV, with a persistent gap in the reported survival outcomes. The paucity of clinical trials focusing on cardiovascular outcomes of patients on long-term ART limits the availability of evidencebased patient management strategies. In a previous metaanalysis of cardiac dysfunction in PLWHIV, left ventricular systolic and diastolic dysfunction was prevalent despite successful ART [5]. Moreover, the levels of inflammation were a strong predictor of systolic dysfunction [5]. Contradictory findings exist on how ART modifies the conventional biomarkers of inflammation [6], and dyslipidaemia [6-8]. These

(c) The Author(s). 2020 Open Access This article is licensed under a Creative Commons Attribution 4.0 International License, which permits use, sharing, adaptation, distribution and reproduction in any medium or format, as long as you give appropriate credit to the original author(s) and the source, provide a link to the Creative Commons licence, and indicate if changes were made. The images or other third party material in this article are included in the article's Creative Commons licence, unless indicated otherwise in a credit line to the material. If material is not included in the article's Creative Commons licence and your intended use is not permitted by statutory regulation or exceeds the permitted use, you will need to obtain permission directly from the copyright holder. To view a copy of this licence, visit http://creativecommons.org/licenses/by/4.0/ The Creative Commons Public Domain Dedication waiver (http://creativecommons.org/publicdomain/zero/1.0/) applies to the data made available in this article, unless otherwise stated in a credit line to the data. 
inconsistent findings further complicate efforts of delineating the precise mechanisms, which link the interplay between the immune continuum and CVDs in PLWHIV on ART. To date, reliable findings on ART induced changes on CVD-risk markers remain elusive. Notably, several studies have reported on the pivotal role that platelets play in linking inflammation and CVD.

Incongruent findings on the levels of platelets activation in PLWHIV have been reported in several observational studies [6-9]. However, the impact of ART on circulating platelets remains unclear. Notably, antiretroviral drugs have been shown to directly activate platelets, in vitro [10], while individual observational studies have reported on conflicting findings of attenuated $[6,11]$ and persistently elevated levels of platelet activation following initiation of ART [7-9, 12, 13]. However, the importance and clinical relevance of evaluating platelet activation in the thrombotic-risk stratification of PLWHIV on ART is confounded by variance in the study setting, duration of ART exposure and differences in the methods of enumerating activated peripheral blood platelets.

This systematic review and meta-analysis, therefore, aimed at providing a comprehensive synthesis of studies reporting on the levels of platelets activation in adult patients living with HIV. The primary objective of this study was to determine whether the levels of platelet activation are elevated in treatment naïve patients with HIV, while the secondary objective was to determine whether the levels of platelet activation are attenuated, following successful ART.

\section{Methods}

This systematic review and meta-analysis was prepared and conducted following the preferred reporting items for systematic reviews and meta-analysis (PRISMA) statement [14]. The review was registered on the prospective register of a systematic reviews registry (PROSPERO) (registration number: CRD42017062393), and the study protocol was published [15]. A comprehensive and systematic search of published studies was conducted to address the following research questions:

1. Are platelets activated in patients living with HIV?

2. Does successful ART attenuate the levels of activated platelets in patients with HIV?

\section{Sources of evidence and search strategy}

A comprehensive search was performed on the MEDL INE, Academic search complete, CINAHL with full-text, Health Source: Nursing/Academic edition, and APA Psycinfo databases using the EBSCOHOST search engine. We further searched the Cochrane Central Register of Clinical Trials (Wiley interface), the metaregister (www. controlled-trials.com $/ \mathrm{mrct} /$ ), ISI web of science, and the Global Index of Medicus. Two reviewers (BBN and PVD) independently searched the electronic databases from inception through the 30th of November 2019 using the following search terms: "Platelets" OR "Thrombocytes" OR "Platelet P-selectin" OR "Platelet CD40L" OR "Platelet monocyte aggregates" OR "Platelet leukocytes aggregates" AND "HIV" OR "HIV-1" AND "Antiretroviral therapy". We further scanned the reference list of selected studies for additional relevant studies. No language restrictions were applied.

\section{Study selection}

The screening of the titles and abstracts of all studies reporting on platelet activation in HIV-infected patients on antiretroviral therapy was independently conducted by three reviewers (BBN, TMN and PVD). Reviews, case reports and pre-clinical studies were excluded. Abstracts from conference proceedings as well as grey literature were also excluded, due to the reported inconsistencies between findings reported in conference abstracts and full publications [16]. The selected studies were also scanned for potential duplicate data publications that may arise from overlapping cohorts reported in different publications. Studies were selected and included in the meta-analysis based on the availability of study-level data required for the effect size estimation.

\section{Data extraction and management}

Two independent reviewers (BBN and PVD) extracted detailed study information and characteristics using a predefined standardised data extraction form. The extracted data items included details of the author, year of publication, original language, sample size, years of follow-up, effect measures reported, gender ratio, levels of coagulation markers, platelet counts, levels of inflammatory markers, mean CD4 counts, HIV-1 RNA levels and HAART regimen. We further extracted the methods used to determine HIV-1 RNA, platelet function and the methods of platelet separation. The extracted data was cross-checked, and inconsistencies were resolved by discussion or referred to a third reviewer (MZ) for arbitration.

\section{Outcomes}

The primary outcomes assessed included levels of platelet activation: reported as the standardised mean difference in soluble platelet P-selectin (sCD62P) or P-selectin (CD62P) levels and soluble CD40L (sCD40L).

\section{Assessment of risk of bias in included studies}

The quality of the included studies was independently assessed by two reviewers (ZM and VM) using the modified Downs and Black checklist which is suitable for 
evaluating both RCTs and non-controlled trials [17]. The checklist assesses four domains which include (I) reporting bias, (II) external validity, (III) internal validity and (IV) selection bias. The overall scores were graded as excellent (26-28), good (20-25), fair (15-19) and poor $(\leq 14)$. These corresponded to those previously reported [18]. Reviewer scores were cross-checked by two reviewers (TMN and VM) and discrepancies were resolved either through discussions or arbitration by BBN.

\section{Data synthesis and statistical analysis}

Descriptive data items on platelet function in adult HIVinfected patients were summarised in studies which inadequate data for a meta-analysis. The Kappa Cohen's Kappa $(\kappa)$ was used to assess the inter-rater agreement of the reviewer's quality agreements and scored as no agreement $(\kappa \leq 0.00)$; none to slight $(\kappa=0.01-0.20)$; fair $(\kappa=0.41-6.0)$; substantial $(\kappa=0.61-0.80)$ and almost perfect $(\kappa=0.81-1.00)$.

\section{Sensitivity analysis and publication bias}

Heterogeneity was assessed using the $I^{2}$ statistic and a value of $50 \%$ was considered as substantial heterogeneity [19], with a $p$ value for heterogeneity testing set at $<0.05$. Continuous outcomes were pooled as standardised mean differences (SMD), and due to the few number of studies included in the meta-analysis, the Hedges' $g$ statistic $(g)$ was used to correct for small study bias. In studies that reported medians and interquartile ranges, we estimated the mean as previously described [20]. Publication bias was assessed using funnel plot analysis, the Egger's regression test. A $p$ value of $<0.05$ represented significant levels of publication bias and the trim and fill method was used to identify and compute an adjusted effect size. The sensitivity analysis was performed to test the unexplained sources heterogeneity and robustness of the reported effect estimates. We assessed the effect of each study on the overall standardised mean difference (SMD), by performing a repeated meta-analysis following the omission of a single-study at a time. All analysis was performed using STATA 16.0 (StataCorp LP, TX, USA). All $p$ values for associations were two-sided and the value of $<0.05$ was considered as significant.

\section{Patient and public involvement}

It was not appropriate or possible to involve patients or the public in the design, or conduct, or reporting, or dissemination plans of our research.

\section{Results}

\section{Study selection}

We identified 831 citations through the electronic database search (390 in MEDLINE, 284 in Academic Search Complete, 73 in CINAHL, 72 in Health Source:
Nursing/Academic edition, and 8 in APA Psycinfo and 4 through other sources). After the initial duplicate removal and screening of abstracts, 827 studies were deemed irrelevant and excluded (Fig. 1). The full texts of the remaining 323 studies were assessed for eligibility, and only 30 studies fulfilled the pre-specified inclusion criteria. The 30 studies were all published in English. These included 2 randomised control trial [21, 22] and 28 non-randomised studies $[6-9,11,12,22-44]$.

\section{Characteristics and quality of eligible studies}

The characteristics of the included studies are shown in Table 1. In total, the included studies comprised of 2325 participants. The risk of bias for all included studies was evaluated by two independent reviewers (TMN and VM) using the Blacks and Downs checklist [17]. (Additional file 2: Table S1). The overall inter-rater reliability was assessed using Cohen's Kappa. The levels of agreement for the various domains were scored as substantial $(\kappa=0.81)$ for the reporting bias and external validity, substantial $(\kappa=0.75)$ for internal validity and almost perfect $(\kappa=0.81)$ for selection bias. Majority of the included studies were rated as poor $(76 \%, n=27)$ while only $20 \%$ of the included studies were rated as fair (Additional file 2: Table S1).

\section{Geographic mapping of the included studies}

The included studies comprised of a total of 18 studies conducted in Europe $[7,8,11,12,25-28,33,34,36,38-$ $41,43,45]$ and 12 studies from the Americas [6, 9, 21, $22,24,31,32,37,46]$. Studies from Italy $[8,26,33,34$, 43], Ireland [11, 36] and USA [6, 9, 21, 22, 24, 30, 32, 46] make the highest contribution (Supplementary Figure 1). The bibliometric analysis based on co-authorship links was performed to assess the potential duplication of published datasets.

\section{Data synthesis and publication bias analysis}

In total, the included studies $(n=30)$ comprised of 1725 HIV-infected patients and $600 \mathrm{HIV}$-negative individuals. Most of the patients with HIV $(71 \%, n=1230)$ were on various antiretroviral drugs (Table 2). The included studies also reported on various effect measures of platelet activation which included soluble P-selectin (sCD62P), soluble glycoprotein VI (sCD36), soluble CD40L and chemokine ligand 5 (RANTES) (Table 3). In nine of the studies, the included cohort of patients with HIV were virologically suppressed $[6,7,31-33,39]$ with only seven studies reporting on patients with CD4 counts $<500$ cells/ $\mathrm{mm}^{3}[8,12]$.

The Egger's regression test suggested evidence of publication bias $(p<0.001)$ (Additional file 1: Table S2). In addition, the funnel plot analysis indicated asymmetry as the trim-and-fill method imputed no missing study for 


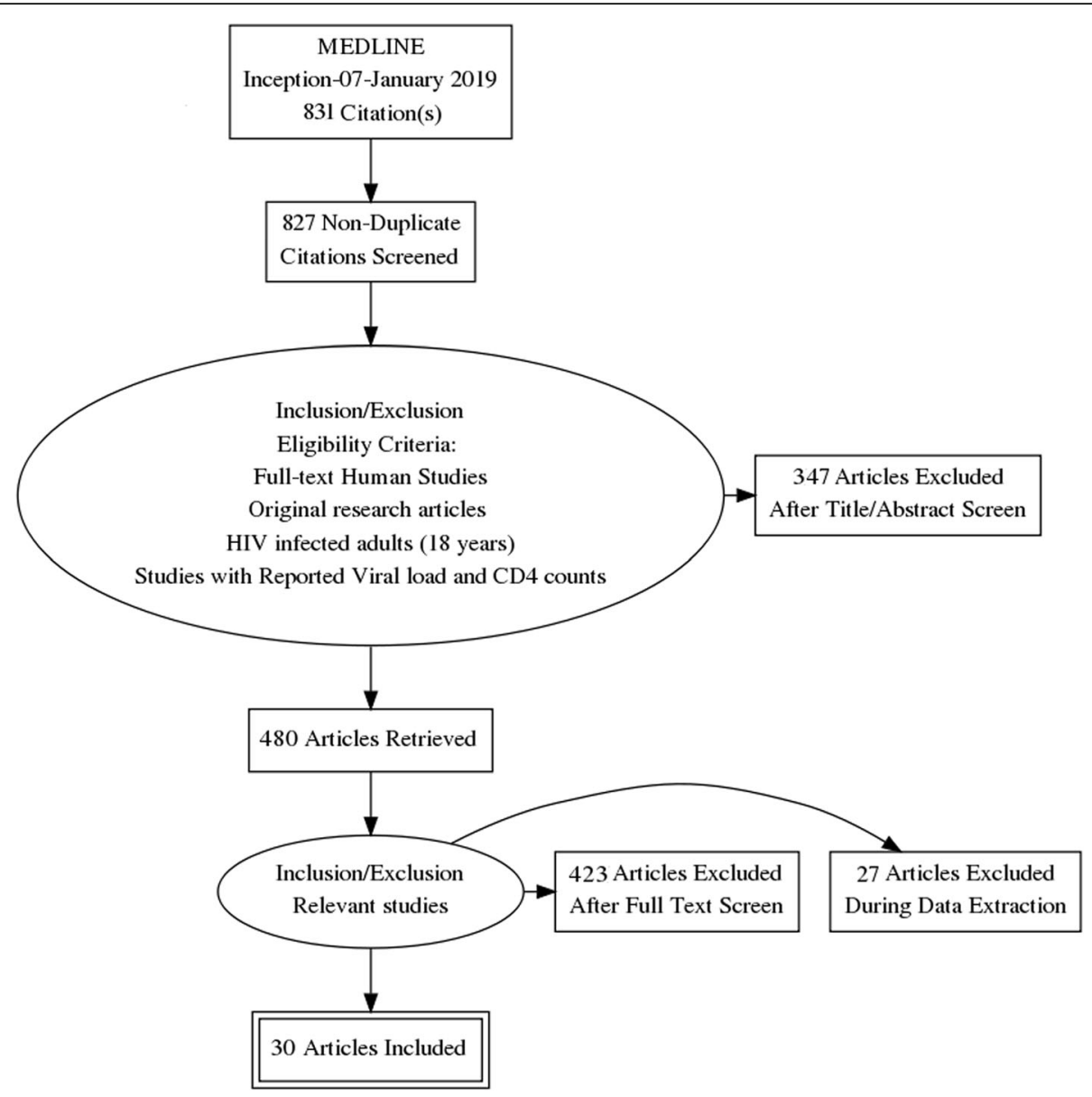

Fig. 1 Flow diagram of the study selection process

the primary platelet activation outcome (Additional file 1: Table S2 and Figure S1). Notably no missing study was imputed (based on the trim and fill method) for comparisons of platelet activation between ART-treated treatment-naïve (Additional file 1: Table S2).

\section{Platelet activation in HIV-infected compared to uninfected patients}

In the majority of the studies $(61 \%, n=17)$, the levels of platelet activation were elevated in HIV-infected patients compared to uninfected controls. The included studies reported on various surrogate markers of platelet activation; these included markers of alpha granule secretion (RANTES) and markers of platelet adhesion and activation (CD62P, CD40L and platelet-monocyte aggregates) (shown in Table 3). In order to assess whether the varying methods used modified the reported effect estimate, we performed a subgroup analysis based on the type of method used in each study. In our subgroup metaanalysis, the primary outcome of platelet activation in HIV-infected patients was compared to uninfected controls. We observed a quantitative effect based on the methodology used to enumerate the levels of platelet activation, whereby in studies using the Luminex, the largest effect size (Hedges' $g$ 3.94 [95\%CI 2.68, 5.19], $p<0.001)$ was compared to ELISA-based technology (Hedges' $g$ 1.55 [95\%CI 0.65, 2.44], $p=0.001$ ) (Fig. 2b). Notably, both methods reported on similar direction of the effect and significantly increased levels of platelet activation in HIV-infected patients.

In all, elevated levels of the surrogate markers of platelet activation, CD40L, P-selectin (CD62P) and the soluble form (sCD62P and sCD40L), were consistently reported in HIV-infected patients [7-9, 11, 12, 23, 24, $27,30,31,33,37-39,41,43,45]$. While a few studies $(17 \%, n=2)$ reported on comparable levels of sCD40L [8], RANTES [26], sCD62P and CD62P [6, 47]. However, the random-effects model, which included 8 studies reporting on 409 treatment-naïve HIV-infected patients and 138 uninfected controls, demonstrated an overall increase in the levels of platelet activation in HIV-infected patients compared to uninfected controls (Fig. 2). The overall bias-corrected standardised mean difference (Hedges' $g$ ) in the levels of platelet activation in 


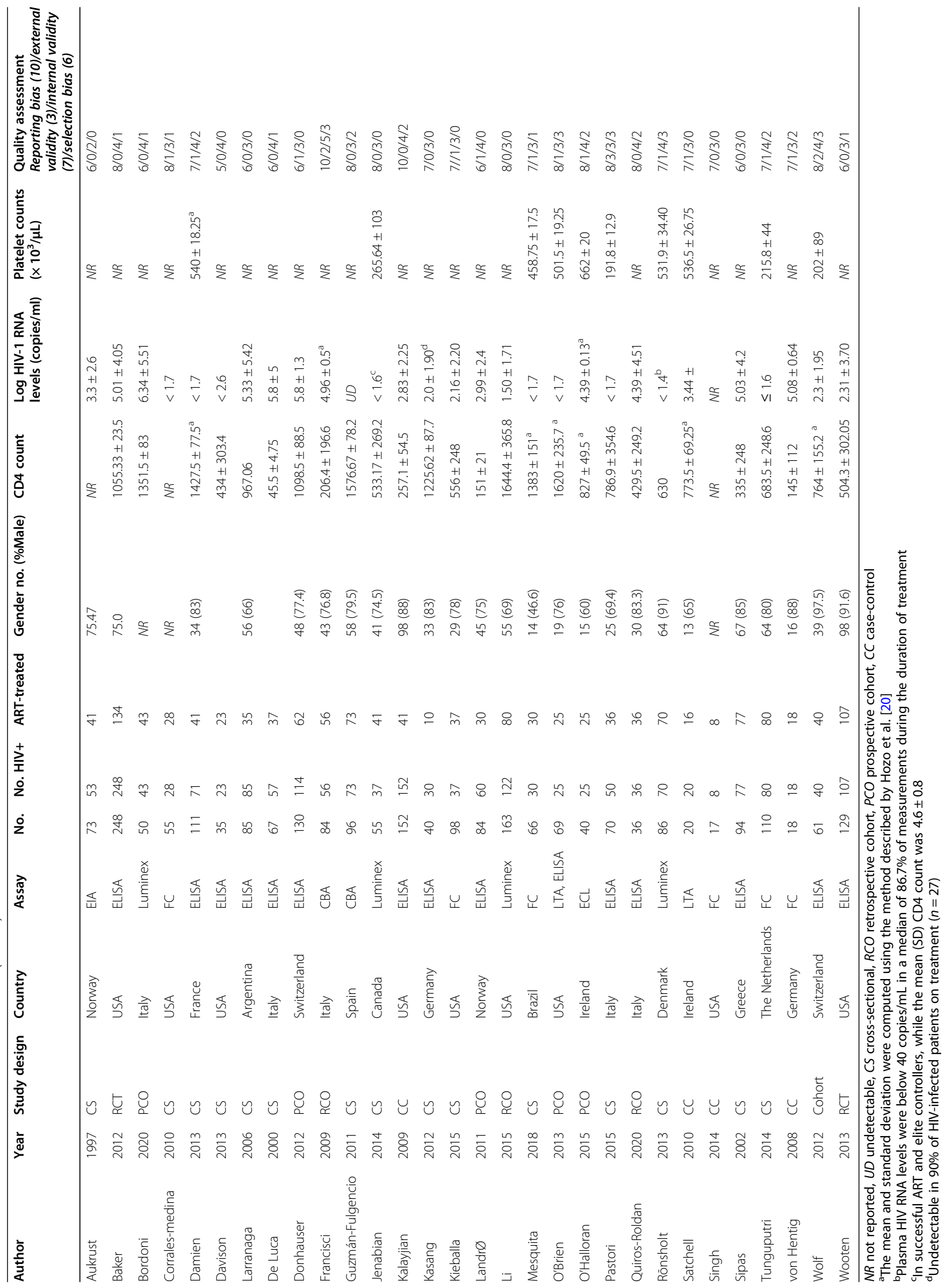


Table 2 A qualitative summary of the findings on platelet function in antiretroviral-treated individuals in the included studies $(n=30)$

\begin{tabular}{|c|c|c|c|c|c|}
\hline \multirow[b]{2}{*}{ Author } & \multirow{2}{*}{ Year } & \multirow{2}{*}{$\begin{array}{l}\text { Antiretroviral } \\
\text { drugs used } \\
\text { NRTI }\end{array}$} & \multicolumn{3}{|c|}{$\begin{array}{l}\text { Summary of findings on platelet activation and function in HIV-infected patients on antiretroviral } \\
\text { therapy }\end{array}$} \\
\hline & & & NNRTI & $\mathrm{PI}$ & \\
\hline Aukrust [45] & 1997 & AZT+3TC (26\%) & - & IDV (26\%) & $\begin{array}{l}\text { The serum RANTES levels were elevated in HIV-1 infected patients. In } \\
\text { addition, the levels of RANTES directly correlated with CD } 4 \text { counts } \\
\text { and inversely correlated with plasma viral load. Notably, the serum } \\
\text { RANTES levels were further increased following the initiation of IDV } \\
\text { containing ART. }\end{array}$ \\
\hline Baker [21] & 2012 & - & $\begin{array}{l}56 \% \text { of } \\
\text { patients NNRTI }\end{array}$ & $\begin{array}{l}29.1 \% \text { of patients on } \\
\text { Pls }\end{array}$ & $\begin{array}{l}\text { The initiation of ART showed no significant reduction in the plasma } \\
\text { levels of SCD62P and SCD40L. In addition, the basal SCD } 40 \mathrm{~L} \text { and } \\
\text { sCD62P showed a direct correlation and inversely correlated with } \\
\text { platelet counts. }\end{array}$ \\
\hline $\begin{array}{l}\text { Bordoni } \\
{[43]}\end{array}$ & 2020 & $\begin{array}{l}\text { All patients } \\
(100 \%) \text { were on } \\
\text { NRTIs }\end{array}$ & $\begin{array}{l}4.6 \% \text { of } \\
\text { patients on } \\
\text { NNRTIs }\end{array}$ & $\begin{array}{l}72.1 \% \text { of patients on } \\
\text { Pls }\end{array}$ & $\begin{array}{l}\text { The plasma RANTES levels were elevated in patients living with HIV. } \\
\text { Moreover, these levels gradually increased despite the initiation of } \\
\text { ART. }\end{array}$ \\
\hline $\begin{array}{l}\text { Corrales- } \\
\text { medina }[6]\end{array}$ & 2010 & $\begin{array}{l}3 \text { TC }(68 \%) \\
\text { ABC }(46 \%) \\
\text { TDF }(43 \%) \\
\text { FTC }(14 \%) \\
\text { AZT }(39 \%) \\
\text { d4T }(14 \%) \\
\text { DDI }(3 \%)\end{array}$ & $\begin{array}{l}\text { EFV (36\%); } \\
\text { NVP }(18 \%)\end{array}$ & $\begin{array}{l}\text { Lopinavir (18\%) } \\
\text { NFV (7\%) } \\
\text { IDV (7\%) } \\
\text { ATV (7\%) } \\
\text { FPV }(7 \%)\end{array}$ & $\begin{array}{l}\text { There were no differences in the levels of CD62P expression in HIV- } \\
\text { infected patients on treatment compared to uninfected controls. } \\
\text { However, the levels of platelet-derived microparticles were elevated } \\
\text { in HIV-infected patients on antiretroviral treatment when compared } \\
\text { to uninfected controls. Moreover, the levels of platelet-derived micro- } \\
\text { particles and activated platelets were similar between patients living } \\
\text { with HIV on PI-based therapy or ABC compared to those who were } \\
\text { not on PIs or ABC. }\end{array}$ \\
\hline
\end{tabular}

Damien [7] 2013 None

Davidson

[46]

De Luca

[26]

Donha

[27]

Francisci [8] 2009 None

Guzmán-

Fulgencio

[28]

Kalayjian

[24]

$2010 \mathrm{~d} 4$

DDI

3TC

(34\%)

EFV (37\%)

patients on NNRTIS

$54 \%$ of patients on $\mathrm{Pls}(\mathrm{PI}$ regime not reported)

LPV/r (29\%)

$200065 \%$ of patients on NRTIs
EFV (86\%) LPV/r (93\%) $\operatorname{NVP}(14 \%) \quad$ NFV $(7 \%)$
Kiebala [9] 2015 NR

Li [30]
$2013 N R$

NR
78.5\% of $\quad 76.7 \%$ of patients on patients on NNRTIS

\section{EFV}

NFV

$L P V / r$

$N R$

$N R$
The levels of platelet activation were elevated in HIV-infected patients compared to uninfected controls. Notably, the plasma levels of SCD62P in HIV-infected patients on antiretroviral treatment were 2fold higher compared to treatment-naive patients and 3-fold higher, compared to uninfected controls.

NNRTI administration was associated with elevated plasma sCD40L. EFV induces the release of SCD40L and also activates the glycogen synthase kinase 3 beta (GSK3 3 ) in platelets.

The baseline RANTES levels were compared between treatment-naïve HIV-infected patients, ART-treated and uninfected controls. Notably RANTES were produced at a higher level in the late-stage HIV infected followed by asymptomatic HIV-infected individuals. In addition, plasma RANTES levels were significantly reduced following treatment.

The levels of SCD40L were elevated in HIV-infected patients when compared to uninfected controls. Notably, these levels were attenuated by successful antiretroviral therapy and were significantly lower when compared to treatment-naïve HIV-infected patients. However, the levels of SCD40L were not normalised following HAART.

The levels of platelet activation were elevated in HIV-infected patients compared to uninfected controls. Notably, only the levels of sCD62P were elevated in patients infected with HIV. While the levels of sCD40L were similar between the HIV and control group. Interestingly, the levels of sCD62P remained persistently elevated post 24 months of antiretroviral therapy.

Patients living with HIV had significantly higher levels of SCD40L and sCD62P despite successful HAART. Notably, these showed no significant associations with the risk of cardiovascular events.

The levels of SCD40L remained unchanged following HAART. In addition, higher baseline SCD40L were associated with the incidence of de novo AIDS-defining illness or mortality despite the initiation of HAART.

The levels of SCD62P were elevated in HIV-infected patients compared to uninfected controls. These elevated levels persisted even during antiretroviral treatment. In, addition platelet activation is not dependent on IKKB signalling

A two-fold increase in $\mathrm{SCD} 40 \mathrm{~L}$ was reported in treatment-naïve HIVinfected elite controllers when compared to ART-treated or uninfected controls. While the levels of RANTES were lower in elite controllers when compared to treatment-naive and uninfected controls. 
Table 2 A qualitative summary of the findings on platelet function in antiretroviral-treated individuals in the included studies ( $n=30$ ) (Continued)

\begin{tabular}{llll}
\hline & $\begin{array}{l}\text { Antiretroviral } \\
\text { drugs used }\end{array}$ & $\begin{array}{l}\text { Summary of findings on platelet activation and function in HIV-infected patients on antiretroviral } \\
\text { therapy }\end{array}$ \\
\cline { 3 - 4 } Author $\quad$ Year & NRTI & NNRTI & PI \\
\hline
\end{tabular}

\begin{tabular}{|c|c|c|c|c|}
\hline & & & & $\begin{array}{l}\text { In addition, the levels of SCD40L and RANTES showed no correlation } \\
\text { with the levels of HIV RNA levels. }\end{array}$ \\
\hline $\begin{array}{l}\text { Jenabian } \\
\text { [23] }\end{array}$ & $2014 N R$ & $N R$ & $N R$ & $\begin{array}{l}\text { The levels of SCD40L were elevated chronically infected treatment- } \\
\text { naïve HIV-infected patients compared to healthy controls. However, } \\
\text { these were normalised following successful ART. }\end{array}$ \\
\hline Kasang [25] & $2012 N R$ & $N R$ & $N R$ & $\begin{array}{l}\text { The levels of SCD4OL were lower in HIV-infected patients on HAART } \\
\text { compared to treatment naïve patients. }\end{array}$ \\
\hline Landrø [12] & $2011 N R$ & $N R$ & $N R$ & $\begin{array}{l}\text { Increased levels of SCD62P, sCD40L, RANTES and NAP-2 in HIV- } \\
\text { infected patients compared to uninfected controls. These levels were } \\
\text { persistently elevated post } 24 \text { months of antiretroviral therapy. In } \\
\text { addition, the levels of NAP-2 were markedly significantly increased } \\
\text { after the initiation of antiretroviral therapy. }\end{array}$ \\
\hline
\end{tabular}

$\begin{array}{lllll}\begin{array}{l}\text { De } \\ \text { Larrañaga } \\ \text { [29] }\end{array} & 2006 & \text { NR } & \text { NR } & 70 \% \\ \begin{array}{l}\text { Mesquita } \\ {[31]}\end{array} & 2018 & 60 \% & 40 \% & 30 \% \\ \text { O'Brien [32] } & 2013 \quad \text { RAL (16\%) } & \begin{array}{l}36 \% \text { of } \\ \text { patients were } \\ \text { on NNRTIs }\end{array} & \begin{array}{l}52 \% \text { of patients were } \\ \text { on Pls }\end{array} \\ & & \text { ABC (20\%) } & \end{array}$

The levels of sCD62P were elevated in HIV patients on HAART

\section{O'Halloran 2015 TDF/FTC [11]

$\begin{array}{lrl}\text { Pastori [33] } & 2015 & \begin{array}{l}\text { 3TC/AZT or } \\ \text { FTC/TDF }\end{array} \\ \begin{array}{l}\text { Quiros- } \\ \text { Roldan [34] }\end{array} & 2020 & \text { RAL (25\%) }\end{array}$

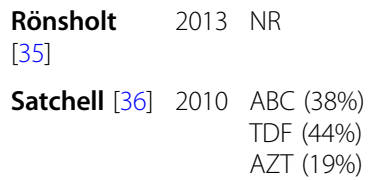

$68 \%$ of None patients were on NNRTIS

$64 \%$ of patients were on NNRTIS
$36 \%$ of patients were on Pls
Increased levels of platelet activation, mitochondrial dysfunction and apoptosis in virologically suppressed HIV-infected individuals. Moreover, HIV-infected patients had elevated levels of platelet exhaustion.

The levels of SCD62P were comparable between HIV-infected patients and uninfected controls. Notably, the levels of urinary 11-dehydro(TX) B2 were elevated in HIV-infected patients compared to uninfected controls. HIV-infected patients who were on antiretroviral therapy and were virally suppressed had elevated levels of activated platelets that were also hyper-reactive. In HIV-infected patients, platelets have a lower activation threshold and display dose-dependent hyper-reactivity. Moreover, Cyclo- oxygenase-1 reactivity remained higher in HIV-infected individuals compared to uninfected controls. Aspirin failed to inhibit arachidonic acid and thromboxane A2 mediated platelet activation.

The levels of sCD62P, sCD40L and sGPVI were elevated in HIVinfected treatment-naïve patients compared to uninfected controls. All markers of platelet activation remained elevated following 3 months of antiretroviral therapy. However, these normalised post 12 months of antiretroviral therapy.

The levels of SCD4OL and platelet oxidative stress were increased in HIV-infected patients compared to uninfected controls.

The levels of RANTES remained unchanged despite successful ART. Notably, the INSTIS (RAL, EVG and DTG) were associated with a 18$21 \%$ increase in RANTES whereas treatment with PI was associated with 32\% decrease in serum RANTES levels although these were not statistically significant.

The levels of SCD62P were comparable between HIV-infected patients on antiretroviral therapy and uninfected controls.

HIV-infected patients on treatment had decreased reactivity to TRAP, ADP and collagen. In treated HIV-infected patients, a decreased platelet response to TRAP was associated with a lower BMI, total LDL cholesterol and elevated CD8 count. While decreased platelet reactivity to ADP was associated with lower levels of hsCRP. Moreover, an increased platelet response to epinephrine in HIV-infected patients was associated with a lower CD4 count and increased CD8 count. Whereas a history of CVDs was associated with decreased response to epinephrine.

The levels of platelet monocyte aggregates are elevated in patients with HIV and these persist despite successful ART

The levels of SCD40L were two-fold higher in HIV-infected patients compared uninfected controls. In addition, these were threefold 
Table 2 A qualitative summary of the findings on platelet function in antiretroviral-treated individuals in the included studies ( $n=30$ ) (Continued)

\begin{tabular}{|c|c|c|c|c|c|}
\hline \multirow[b]{2}{*}{ Author } & \multirow[b]{2}{*}{ Year } & \multirow{2}{*}{$\begin{array}{l}\text { Antiretroviral } \\
\text { drugs used } \\
\text { NRTI }\end{array}$} & \multicolumn{3}{|c|}{$\begin{array}{l}\text { Summary of findings on platelet activation and function in HIV-infected patients on antiretroviral } \\
\text { therapy }\end{array}$} \\
\hline & & & NNRTI & PI & \\
\hline & & & & & higher following $8-12$ months of HAART. \\
\hline $\begin{array}{l}\text { Tunguputri } \\
{[39]}\end{array}$ & 2014 & $\begin{array}{l}\text { RAL (31.25\%) } \\
\operatorname{ABC}(6 \%)\end{array}$ & $\begin{array}{l}\text { EFV; RPV or } \\
\text { NVP } \\
\text { ABC } 9 \%\end{array}$ & $\begin{array}{l}\text { RTV-boosted PI } \\
\text { (DRV, ATV or LPV) } \\
\text { ABC (3\%) }\end{array}$ & $\begin{array}{l}\text { Increased levels of platelet monocyte aggregates in HIV-infected pa- } \\
\text { tients persist despite effective ART. Notably, RAL-based regimen low- } \\
\text { ered platelet hyperactivity and platelet monocyte aggregates. While } \\
\text { ABC-treated patients showed a trend of higher platelet reactivity. }\end{array}$ \\
\hline Wolf [41] & 2012 & $\begin{array}{l}2.5 \% \text { of } \\
\text { patients were } \\
\text { on NRTIs }\end{array}$ & $\begin{array}{l}\text { NVP }(10 \%) \\
\operatorname{EFV}(10 \%)\end{array}$ & $\begin{array}{l}\text { RTV }(5 \%) \\
\text { IDV (5\%) } \\
\text { SQV (37.5\%) }\end{array}$ & $\begin{array}{l}\text { The levels of platelet activation were higher in HIV-infected patients } \\
\text { when compared to controls. The levels of sCD62P and SCD40L did } \\
\text { not decrease during antiretroviral therapy. }\end{array}$ \\
\hline $\begin{array}{l}\text { Von Hentig } \\
{[40]}\end{array}$ & 2008 & - & - & $\begin{array}{l}\text { SQV/LPV/r (22\%) } \\
\text { SQV/RTV (61\%) } \\
\text { FPV (11\%) } \\
\text { FPV/LPV/r (6\%) }\end{array}$ & $\begin{array}{l}\text { Short-term 4-week ART treatment with Pls enhanced the levels of } \\
\text { CD40L and CD41 activity on platelets. Whereas CD62P levels were } \\
\text { comparable after ART. }\end{array}$ \\
\hline $\begin{array}{l}\text { Wooten } \\
{[22]}\end{array}$ & 2013 & NR & NR & NR & $\begin{array}{l}\text { The plasma levels of RANTES were significantly elevated in patients } \\
\text { with HIV on stable HAART for a duration of } 6 \text { months. }\end{array}$ \\
\hline
\end{tabular}

treatment-naïve HIV-infected patients compared to uninfected controls was 2.00 [95\%CI 1.05, 2.94]; $z=4.12$, $p<0.001$. Notably, the levels of heterogeneity were high $\left(I^{2}=95.91 \%, p<0.01\right)$. Therefore, we performed a subgroup analysis to explore the sources of heterogeneity based on the reported marker of platelet activation. The test for subgroup effects showed a significant subgroup effect $(p<0.001)$ (Fig. 2a). This suggests that the reported pooled effect estimate was influenced by the various markers of platelet activation reported in the included studies.

\section{Platelet P-selectin levels in treatment-naïve HIV-infected patients}

A total of 16 included studies reported on the levels of P-Selectin (CD62P) in untreated HIV-1-infected patients compared to ART-treated and uninfected controls [6-8, $11,12,21,28,29,31,32,35,37,39-41]$. However, only two studies [12, 41] had adequate study-level data and were included in the subgroup meta-analysis. The pooled effect estimate included 146 participants comprising 101 $\mathrm{HIV}$-infected patients and 45 uninfected controls. Interestingly, the sCD62P levels were elevated in patients with HIV when compared to uninfected controls (Hedges' $g$ 0.57 [95\%CI 0.22, 0.93], $p=0.002)$. Moreover, there were low levels of heterogeneity $\left(I^{2}=0 \%\right)$ (Fig. 2).

\section{Soluble CD40L levels in treatment-naïve HIV-infected patients}

A total of 384 participants were included in the subgroup meta-analysis of 6 studies. This comprised of

Table 3 Reported markers of platelet activation in treatment-naïve and ART-treated HIV-infected patients

\begin{tabular}{|c|c|c|c|}
\hline \multirow{2}{*}{$\begin{array}{l}\text { Effect } \\
\text { measure }\end{array}$} & \multirow{2}{*}{$\begin{array}{l}\text { No. } \\
\text { studies }\end{array}$} & \multicolumn{2}{|l|}{ Levels of platelet activation in PLWHIV } \\
\hline & & Treatment naïve & Post-ART \\
\hline sCD62P & 12 & $\begin{array}{l}\text { Increased }[6-9,11,21,28,31,33,41] \\
\text { similar between PLWHIV and controls [6] }\end{array}$ & Increased $[6-9,12,21,28,29,31] ;$ decreased $[11,35,40]$ \\
\hline sCD40L & 14 & $\begin{array}{l}\text { Increased }[6-8,10,13,30,34,36-38,43] \\
\text { Similar between PLWHIV and controls [8] }\end{array}$ & $\begin{array}{l}\text { Increased }[7,11,21,24,27,28,38,40,46] \text {; Increased in NNRTI-treated patients } \\
{[25,41] \text {; Decreased in }[7,28,37-39]}\end{array}$ \\
\hline sGPVI & 1 & Increased [11] & Decreased [11] \\
\hline RANTES & 6 & Increased [10, 29-33] & Increased [10, 29, 31, 45]; Decreased [26] \\
\hline CD62P & 3 & Increased [9] & $\begin{array}{l}\text { Increased [31]; } \\
\text { Decreased In RAL-treated patients; } \\
\text { Similar between PLWHIV and controls [6] }\end{array}$ \\
\hline PMAs & 2 & Increased [39] & Decreased in RAL compared to NNRTI- and PI-treated PLWHIV [39] \\
\hline
\end{tabular}

sCD62P soluble P-selectin, sCD40L soluble CD40 Ligand, sGPVI soluble glycoprotein VI, RANTES chemokine ligand 5, CD62P P-Selectin, PMAs platelet monocyte aggregates, $R A L$ raltegravir 


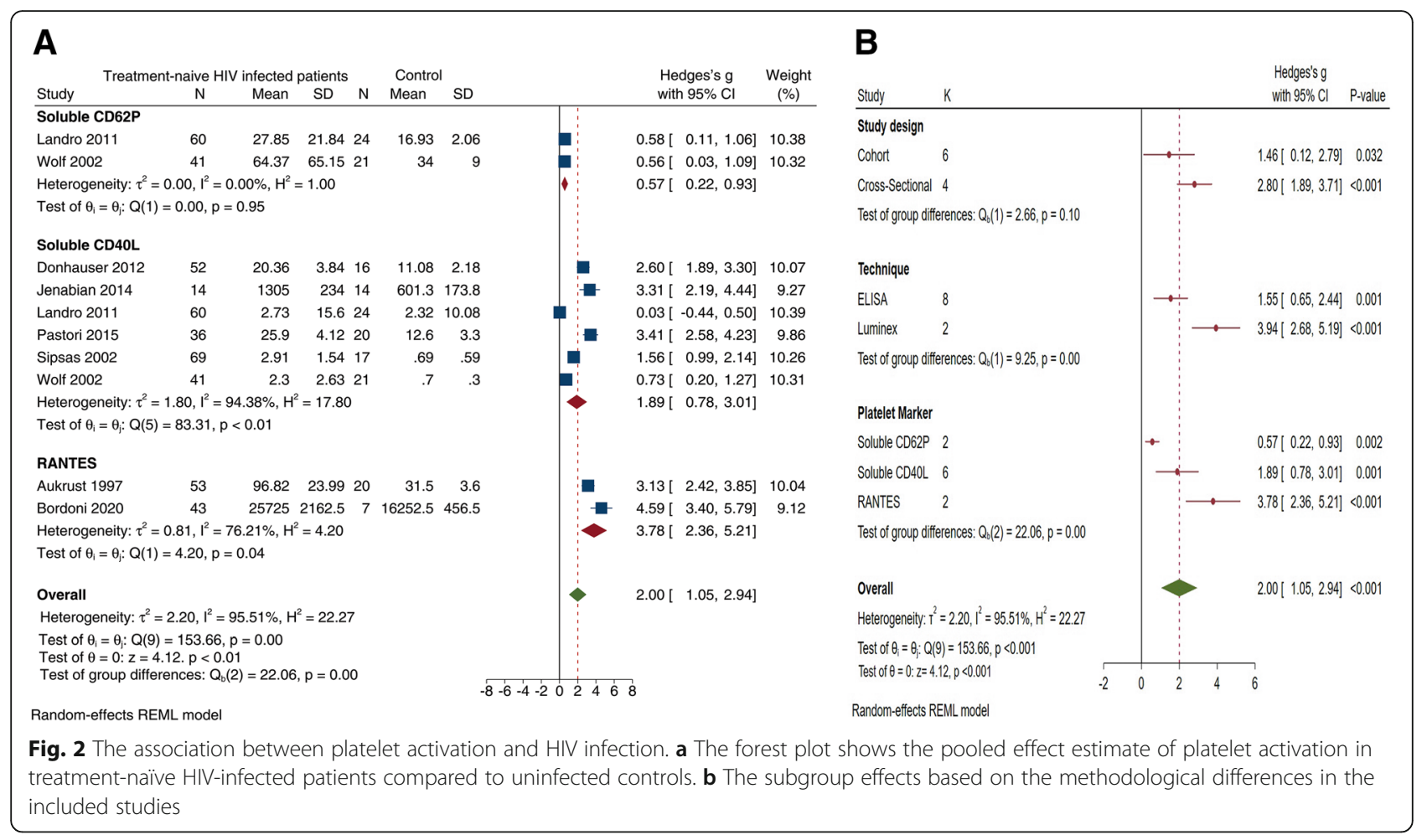

272 treatment-naïve HIV-infected patients and 112 uninfected controls. The levels of sCD40L were elevated in treatment-naïve HIV-infected patients compared to controls (Hedges' $g$ 1.89 [95\%CI 0.78, 3.01], $p=0.001$ ) (Fig. 2b). Notably, the levels of heterogeneity were high amongst the included studies $\left(I^{2}=94.38 \%\right)$. We, therefore, explored other sources of heterogeneity which included differences in the study design, and the methodology used to measure the levels of platelet activation (Fig. $2 b$ ).

The test for group differences showed a significant interaction effect based on the reported technique or methodology used $(p<0.01)$ and reported marker of platelet activation $(p<0.001)$ (Fig. 3b). Notably, there were no significant between-study differences on the reported pooled estimates based on the varying study designs $(p=0.10)$.

\section{RANTES levels in treatment-naïve HIV-infected patients}

A total of 123 participants from 2 studies [43, 45] were included in this subgroup analysis (Fig. 2). In all, this included 96 treatment-naïve HIV-infected patients and 27 uninfected controls. The pooled estimate showed significantly increased levels of RANTES in treatment-naive HIV-infected patients compared to uninfected controls (Hedges' $g$ 3.78 [95\%CI 2.36, 5.21], $p=<0.001$ ) (Fig. 2b). However, the levels of heterogeneity were high amongst the studies included in this subgroup $\left(I^{2}=76.21 \%\right)$.

\section{Platelet activation in HIV-infected patients on} antiretroviral therapy compared to treatment-naïve HIVinfected patients

Elevated levels of platelet activation, exhaustion and apoptosis persist even during successful ART [6-9, 11, $12,21,22,24,27-29,31-41,43,45-47]$. The use of NNRTIs was associated with elevated sCD40L levels [41], while others reported that ART did not affect the elevated levels of sCD40L, RANTES and urinary 11dehydrothromboxane B2 levels [7, 21, 24, 34, 47]. In addition, plasma sCD62P and sCD40L levels were 2-3fold higher in treated HIV-infected patients compared with treatment-naïve HIV-infected patients [7, 38]. Congruently, persistently activated elevated levels of platelet reactivity have been reported following 6 to 24 months of initiating treatment [7, 8, 22, 38-41, 47]. In contrast, three studies reported on the normalisation of platelet activation levels following 12 months of ART [11, 23, 26]. Moreover, ART-treated patients had higher levels of spontaneous platelet aggregation in response to submaximal concentrations of various endogenous platelet agonists [47].

Only 18 studies had adequate study-level data and were included in the meta-analysis $[6-8,11,12,22,23$, $26-28,30,32,33,35,37-41,43,45]$. The pooled estimates showed elevated levels of platelet activation in ART-treated patients compared to controls (Hedges' $g$ 2.05 [95\%CI 0.58, 3.52]; $z=2.71, p=0.0067$ ) (Fig. 3), and 


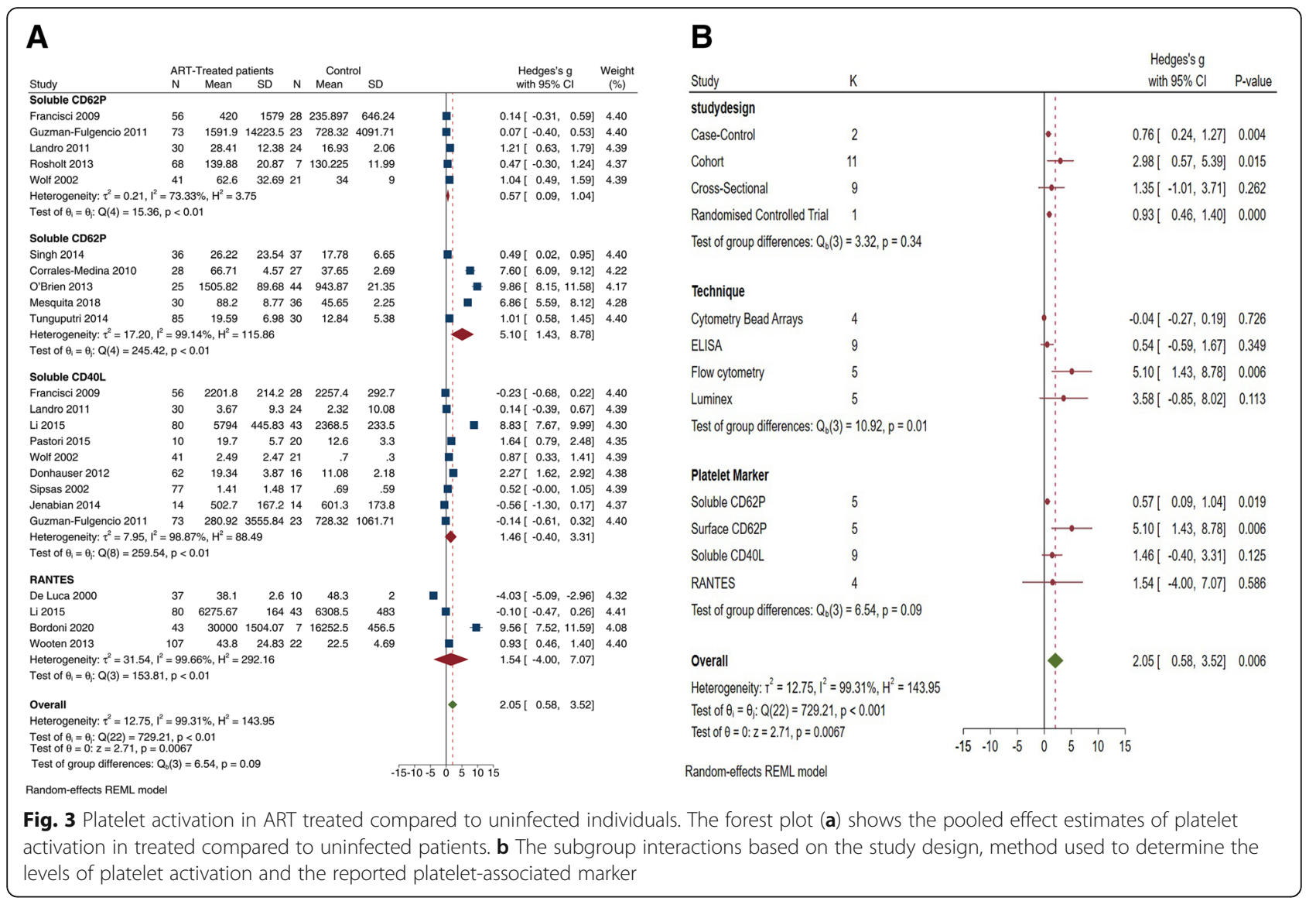

these elevated levels were comparable between ARTtreated patients with HIV and treatment-naïve patients (Hedges' $g$ 0.21 [95\%CI - 0.69, 1.10], $\mathrm{z}=0.83 p=0.4080$ ) (Fig. 4). However, these levels of heterogeneity were substantial $\left(I^{2}=98.68 \%\right)$. To explore the sources of unexplained heterogeneity, we then conducted a subgroup analysis based on the reported effect measure of platelet activation within the included studies (Fig. 3a).

In all, the levels of both surface CD62P (Hedges' $g 5.10$ [95\%CI 1.45, 8.78], $p=0.006$ ) and sCD62P (Hedges' $g$ 0.57 [95\%CI 0.09, 1.04], $p=0.019$ ) remained significantly elevated in patients with HIV on ART when compared to uninfected controls (Fig. 3). We further conducted a subgroup meta-analysis based on the study design, the technique used and reported marker of platelet activation (Fig. 3b). The test for subgroup differences demonstrated a statistically significant interaction effect, in the subgroup based on the technique $(p<0.01)$ and marker used to enumerate activated platelets $(p<0.09)$.

\section{Discussion}

To date, this is the first systematic review and metaanalysis of studies reporting on platelet activation in adult patients living with HIV. We retrieved and analysed 30 studies that reported on platelet activation in adult
PLWHIV on ART. Several of these studies $(50 \%, n=15)$ reported on data obtained from serum or plasma samples using enzyme-linked immunosorbent assays. While the methods used to measure platelet activation included the detection of surface markers of platelet activation using flow cytometry $(23 \%, n=7)$, Luminex technology $(10 \%$, $n=3$ ) and immunoassay-based methods (50\%, $n=15$ ). Platelet function was only evaluated in a few studies $(1.66 \%, n=2)$ using light transmission aggregometry. Notably, the subgroup meta-analysis showed that methodological variance may influence the reported levels of platelet activation, with studies employing the Luminex technology showing a larger pooled estimate when compared to ELISA-based methods.

In all, several studies reported on elevated levels of soluble, CD62P (sCD62P) and CD40L (sCD40L), in PLWHIV compared to uninfected controls (Table 3). This supports the finding of increased levels of platelet activation in adult HIV-infected patients [7, 8, 11, 12, 33, 41]. Moreover, in follow-up studies, these levels were shown to persist following 3 to 24 months of successful ART [8, 12, $22,38,47]$. Although ART attenuated the levels of platelet activation in patients who were not receiving protease inhibitors (PIs) [11], in those patients on PI-based therapy, the levels of platelet activation persisted despite successful 


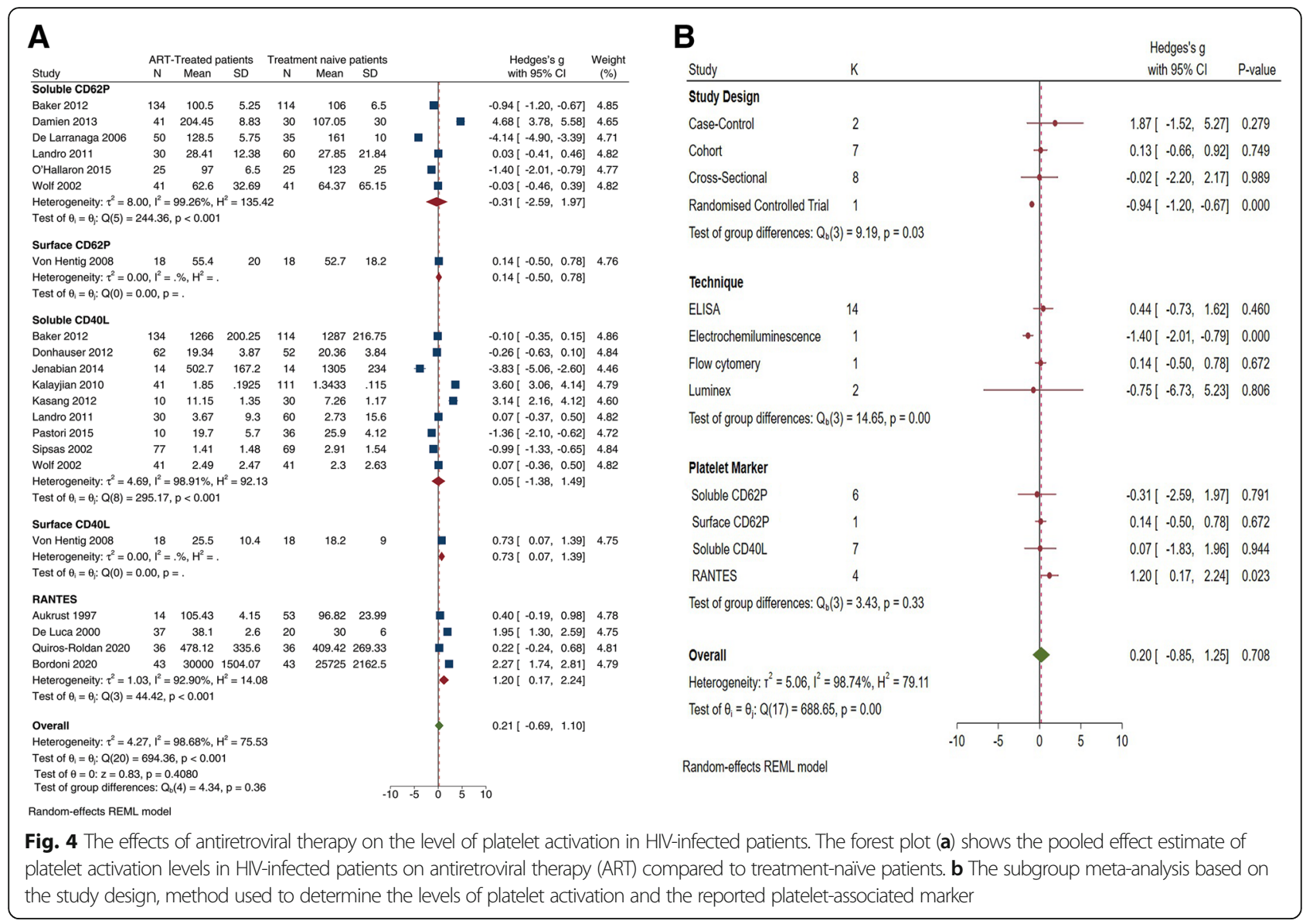

ART [21, 24, 28, 29, 39, 41, 43, 45-47]. Moreover, the levels of platelet activation were 2 -fold higher in patients on PI-based therapy compared to treatment naive patients with HIV [7, 30, 38]. Notably, different measures of platelet activation were reported in the included studies (Table 3); the vast majority of the studies report on congruent findings of elevated levels of platelet activation despite achieving viral suppression, although a few of the included observational studies reported on discordant findings, on the levels of CD62P and CD40L in ARTtreated patients living with $\operatorname{HIV}[7,8]$.

To our knowledge, this is the first pooled analysis of platelet activation levels reported in patients living with HIV. The primary objective of the planned meta-analysis was to determine the association between the levels of platelet activation in HIV-infected treatment-naïve patients. While the secondary objective of this analysis of pooled data was to assess whether effective ART attenuates the levels of platelet activation in patients living with HIV. In all, the levels of platelet activation were elevated in adult patients living with HIV when compared to uninfected controls (Fig. 2). Notably, this supports the previously reported findings of elevated levels of platelet activation in HIV-infected patients $[6,13,36,48]$. The current study adds value in highlighting that $\mathrm{SCD} 40 \mathrm{~L}$ levels are increased at greater magnitude when compared to levels of sCD62P in treatment-naïve HIV-infected patients. These findings further highlight the potential benefit of using sCD40L and sCD62P in thrombotic-risk profiling of PLWHIV on ART, as sCD62P is associated with platelet and vascular activation.

The present meta-analysis of patients with HIV on ART and treatment-naïve infected patients suggests that ART had no effect on the levels of platelet activation, although the RANTES, sCD40L and surface CD40L levels were comparable following successful ART (Fig. 3b). In contrast, the sC62P and surface CD62P levels remained significantly increased following effective ART (Fig. 3b). Differences in the treatment regimens may account for the incongruent effect estimates. In fact, all studies reporting on patients receiving PI-based ART showed elevated levels of platelet activation despite successful viral suppression [6-8, 39, 47].

The strengths of this review include the comprehensive search and data extraction which was independently performed by two reviewers. The interrater agreement was high for most of the risk of bias. Although the included studies showed high levels of 
heterogeneity, the potential risk of bias of these studies was scored as fair. The presented cumulative evidence is limited by the lack of adequate randomised control trials and reporting of ART regimen used. Due to the lack of adequate number of RCTs addressing the changes in platelet activation following ART, we considered and included observational studies alongside RCTs in the meta-analysis [49]. The included studies were scored low in the external validity, thus limiting the generalisability of these findings. Lastly, the pooled effect estimates on the levels of platelet activation were derived from studies conducted mainly in the Americas and countries in Europe. Caution should be taken in extrapolating these findings into a different geographic setting.

\section{Conclusion}

This meta-analysis provides evidence that the levels of soluble CD62P and CD40L are elevated in HIV-infected patients and that SCD62P levels persist despite successful therapy. Overall, we report on elevated levels of platelet activation in adult PLWHIV which persist despite successful ART.

\section{Supplementary information}

Supplementary information accompanies this paper at https://doi.org/10. 1186/s12916-020-01801-9.

Additional file 1: Table S1. Search strategy used on the EBSCOHOST search engine. Table S2. Publication bias analysis. Figure S1. Analysis of publication bias. The funnel plots were visually inspected for publication bias in the included studies.

Additional file 2: Table S2. Risk of bias analysis.

\section{Acknowledgements}

PV Dludla was partially supported as a Post-Doctoral Fellow by funding from the Research Capacity Division of the South African Medical Research Council (SAMRC) through its division of Research Capacity Development under the Intra-mural Postdoctoral Fellowship Programme from funding received from the South African Treasury. The content hereof is the sole responsibility of the authors and do not necessarily present the official views of SAMRC or the funders.

\section{Authors' contributions}

BBN and PVD conceptualised, designed, and drafted this manuscript. VM, KM and TMN performed the literature search; BBN, PVD and TMN conducted the screening and study selection. BBN analysed the data, and ZM cross-checked the extracted data. All authors read and approved the final manuscript.

\section{Funding}

The current study is partially funded by the University of KwaZulu-Natal (UKZN) Developing Research Innovation, Localisation and Leadership in South Africa (DRILL) fellow. DRILL is an NIH D43 grant (D43TW010131) awarded to UKZN in 2015 to support a research training and induction programme for early-career academics.

\section{Availability of data and materials}

The authors confirm that the data supporting the findings of this study are available within the article and its additional files.

Ethics approval and consent to participate

Not applicable.

\section{Competing interests}

The authors declare no competing interests associated with this manuscript.

\section{Author details}

${ }^{1}$ School of Laboratory Medicine and Medical Sciences (SLMMS), College of Health Sciences, University of KwaZulu-Natal, Private Bag X54001, Durban 4000, South Africa. ${ }^{2}$ Biomedical Research and Innovation Platform (BRIP), Medical Research Council (MRC), Tygerberg, Cape Town, South Africa.

Received: 14 May 2020 Accepted: 29 September 2020

Published online: 18 November 2020

\section{References}

1. Trickey A, May MT, Vehreschild J-J, Obel N, Gill MJ, Crane HM, et al. Survival of HIV-positive patients starting antiretroviral therapy between 1996 and 2013: a collaborative analysis of cohort studies. Lancet HIV. 2017;4(8):e349-56.

2. Samji H, Cescon A, Hogg RS, Modur SP, Althoff KN, Buchacz K, et al. Closing the gap: increases in life expectancy among treated HIV-positive individuals in the United States and Canada. PLoS One. 2013;8(12):e81355.

3. Bhatta DN, Adhikari R, Karki S, Koirala AK, Wasti SP. Life expectancy and disparities in survival among HIV-infected people receiving antiretroviral therapy: an observational cohort study in Kathmandu. Nepal BMJ Glob Heal. 2019;4(3):e001319.

4. Palella FJ Jr, Baker RK, Buchacz K, Chmiel JS, Tedaldi EM, Novak RM, et al. Increased mortality among publicly insured participants in the HIV outpatient study despite HAART treatment. Aids. 2011;25(15):1865-76.

5. Cerrato E, D'Ascenzo F, Biondi-Zoccai G, Calcagno A, Frea S, Grosso Marra $W$, et al. Cardiac dysfunction in pauci symptomatic human immunodeficiency virus patients: a meta-analysis in the highly active antiretroviral therapy era. Eur Heart J. 2013:34(19):1432-6.

6. Corrales-Medina VF, Simkins J, Chirinos JA, Serpa JA, Horstman LL, Jy W, et al. Increased levels of Platelet microparticles in HIV infected patients with good response to highly active antiretroviral therapy (HAART). JAIDS. 2010; 54(2):217-8

7. Damien P, Cognasse F, Lucht F, Suy F, Pozzetto B, Garraud O, et al. Highly active antiretroviral therapy alters inflammation linked to platelet cytokines in HIV-1-infected patients. J Infect Dis. 2013;208:868-70.

8. Francisci D, Giannini S, Baldelli F, Leone M, Belfiori B, Guglielmini G, et al. HIV type 1 infection, and not short-term HAART, induces endothelial dysfunction. Aids. 2009;23(5):589-96.

9. Kiebala M, Singh MV, Piepenbrink MS, Qiu X, Kobie JJ, Maggirwar SB. Platelet activation in human immunodeficiency virus type-1 patients is not altered with cocaine abuse. PLoS One. 2015;10(6):1-15.

10. Taylor KA, Smyth E, Rauzi F, Cerrone M, Khawaja AA, Gazzard B, et al. Pharmacological impact of antiretroviral therapy on platelet function to investigate human immunodeficiency virus-associated cardiovascular risk. Br J Pharmacol. 2019;176(7):879-89.

11. O'Halloran JA, Dunne E, Gurwith M, Lambert JS, Sheehan GJ, Feeney ER, et al. The effect of initiation of antiretroviral therapy on monocyte, endothelial and platelet function in HIV-1 infection. HIV Med. 2015;16(10):608-19.

12. Landrø L, Ueland T, Otterdal K, Frøland SS, Aukrust P. Persistently raised plasma levels of platelet-derived inflammatory mediators in HIV-infected patients during highly active antiretroviral therapy. J Thromb Haemost. 2011;9(5):1075-7.

13. Mayne E, Funderburg NT, Sieg SF, Asaad R, Kalinowska M, Rodriguez B, et al. Increased platelet and microparticle activation in HIV infection: upregulation of Pselectin and tissue factor expression. J Acquir Immune Defic Syndr. 2012;59(4):340.

14. Moher D, Liberati A, Tetzlaff J, Altman DG. Preferred reporting items for systematic reviews and meta-analyses: the PRISMA statement. J Clin Epidemiol. 2009;62(10):1006-12.

15. Nkambule BB, Mkandla Z, Mutize T, Dludla PV. Platelet function and cardiovascular risk in adult HIV-infected patients on HAART: a protocol for a systematic review and meta-analysis. BMJ Open. 2017;7(12):e019468.

16. Li G, Abbade LPF, Nwosu I, Jin Y, Leenus A, Maaz M, et al. A scoping review of comparisons between abstracts and full reports in primary biomedical research. BMC Med Res Methodol. 2017;17(1):181.

17. Downs $\mathrm{SH}$, Black N. The feasibility of creating a checklist for the assessment of the methodological quality both of randomised and non-randomised studies of health care interventions. J Epidemiol Community Health. 1998; 52(6):377-84. 
18. Hooper P, Jutai JW, Strong G, Russell-Minda E. Age-related macular degeneration and low-vision rehabilitation: a systematic review. Can J Ophthalmol. 2008;43(2):180-7.

19. Higgins J, Thompson SG. Quantifying heterogeneity in a meta-analysis. Stat Med. 2002;21(11):1539-58.

20. Hozo SP, Djulbegovic B, Hozo I. Estimating the mean and variance from the median, range, and the size of a sample. BMC Med Res Methodol. 2005;5(1):13.

21. Baker JV, Neuhaus J, Duprez D, Freiberg MS, Bernardino JI, Badley AD, et al. A novel marker of endothelial dysfunction. J Acquir Immune Defic Syndr. 2012;60(2):128-34

22. Wooten JS, Nambi P, Gillard BK, Pownall HJ, Coraza I, Scott LW, et al. Intensive lifestyle modification reduces Lp-PLA2 in dyslipidemic HIV/HAART patients. Med Sci Sports Exerc. 2013;45(6):1043-50.

23. Jenabian MA, Patel M, Kema I, Kanagaratham C, Radzioch D, Thébault $P$, et al. Distinct tryptophan catabolism and Th17/Treg balance in HIV progressors and elite controllers. PLoS One. 2013;8(10):1-13.

24. Kalayjian RC, Machekano RN, Rizk N, Robbins GK, Gandhi RT, Rodriguez BA, et al. Pretreatment levels of soluble cellular receptors and Interleukin-6 are associated with HIV disease progression in subjects treated with highly active antiretroviral therapy. J Infect Dis. 2010;201(12):1796-805.

25. Kasang C, Ulmer A, Donhauser N, Schmidt B, Stich A, Klinker H, et al. HIV patients treated with low-dose prednisolone exhibit lower immune activation than untreated patients. BMC Infect Dis. 2012;12(1)1-12.

26. De Luca A, Giancola ML, Cingolani A, Ammassari A, Murri R, Antinori A. Circulating levels and ex vivo production of $\beta$-chemokines, interferon $\gamma$, and interleukin 2 in advanced human immunodeficiency virus type 1 infection: the effect of protease inhibitor therapy. AIDS Res Hum Retrovir. 2000;16(9):835-43.

27. Donhauser N, Pritschet $K$, Helm M, Harrer $T$, Schuster P, Ries M, et al. Chronic immune activation in HIV-1 infection contributes to reduced interferon alpha production via enhanced CD40:CD40 ligand interaction. PLoS One. 2012;7(3).

28. Guzmán-Fulgencio M, Medrano J, Rallón N, Echeverria-Urabayen A, Miguel Benito J, Restrepo C, et al. Soluble markers of inflammation are associated with Framingham scores in HIV-infected patients on suppressive antiretroviral therapy. J Inf Secur. 2011;63(5):382-90.

29. De Larrañaga GF, Perés Wingeyer SDA, Puga LM, Alonso BS, Benetucci JA. Relationship between hepatitis $C$ virus ( $\mathrm{HCV}$ ) and insulin resistance, endothelial perturbation, and platelet activation in HIV-HCV-coinfected patients under highly active antiretroviral treatment. Eur J Clin Microbiol Infect Dis. 2006;25(2):98-103.

30. Li JZ, Arnold KB, Lo J, Dugast A-S, Plants J, Ribaudo HJ, et al. Differential levels of soluble inflammatory markers by human immunodeficiency virus controller status and demographics. In: Open forum infectious diseases; 2015.

31. Mesquita EC, Hottz ED, Amancio RT, Carneiro AB, Palhinha L, Coelho LE, et al. Persistent platelet activation and apoptosis in virologically suppressed HIV-infected individuals. Sci Rep. 2018;8(1):1-10.

32. O'Brien M, Montenont E, Hu L, Nardi MA, Valdes V, Merolla M, et al. Aspirin attenuates platelet activation and immune activation in HIV-1-infected subjects on antiretroviral therapy: a pilot study. J Acquir Immune Defic Syndr. 2013;63(3):280.

33. Pastori D, Esposito A, Carnevale R, Bartimoccia S, Novo M, Fantauzzi A, et al. HIV-1 induces in vivo platelet activation by enhancing platelet NOX2 activity. J Inf Secur. 2015;70(6):651-8.

34. Quiros-Roldan E, Castelli F, Bonito A, Vezzoli M, Calza S, Biasiotto G, et al. The impact of integrase inhibitor-based regimens on markers of inflammation among HIV na\{ไ" 'i\}ve patients. Cytokine. 2020;126:154884.

35. Rönsholt FF, Ullum H, Katzenstein TL, Gerstoft J, Ostrowski SR. Persistent inflammation and endothelial activation in HIV-1 infected patients after 12 years of antiretroviral therapy. PLoS One. 2013;8(6):1-5.

36. Satchell CS, Cotter AG, O'Connor EF, Peace AJ, Tedesco AF, Clare A, et al. Platelet function and HIV: a case-control study. Aids. 2010;24(5):649-57.

37. Singh MV, Davidson DC, Jackson JW, Singh VB, Silva J, Ramirez SH, et al. Characterization of platelet--monocyte complexes in HIV-1--infected individuals: possible role in HIV-associated neuroinflammation. J Immunol. 2014;192(10):4674-84.

38. Sipsas NV, Sfikakis PP, Kontos A, Kordossis T. Levels of soluble CD40 ligand (CD154) in serum are increased in human immunodeficiency virus type 1infected patients and correlate with CD4+ T-cell counts. Clin Diagn Lab Immunol. 2002;9(3):558-61.

39. Tunjungputri RN, Van Der Ven AJ, Schonsberg A, Mathan TS, Koopmans P, Roest M, et al. Reduced platelet hyperreactivity and plateletmonocyte aggregation in HIV-infected individuals receiving a raltegravir-based regimen. Aids. 2014;28(14):2091-6.

40. von Hentig N, Förster AK, Kuczka K, Klinkhardt U, Klauke S, Gute P, et al. Platelet-leucocyte adhesion markers before and after the initiation of antiretroviral therapy with HIV protease inhibitors. J Antimicrob Chemother. 2008;62(5):1118-21.

41. Wolf K, Tsakiris DA, Weber R, Erb P, Battegay M. Antiretroviral therapy reduces markers of endothelial and coagulation activation in patients infected with human immunodeficiency virus type 1. JnfectDis. 2002; 185(0022-1899 (Print):456-62.

42. Liani R, Halvorsen B, Sestili S, Handberg A, Santilli F, Vazzana N, et al. Plasma levels of soluble CD36, platelet activation, inflammation, and oxidative stress are increased in type 2 diabetic patients. Free Radic Biol Med. 2012;52(8): 1318-24.

43. Bordoni V, Sacchi A, Casetti R, Cimini E, Tartaglia E, Pinnetti C, et al. Impact of ART on dynamics of growth factors and cytokines in primary HIV infection. Cytokine. 2020;125:154839. https://doi.org/10.1016/j.cyto.2019.154839.

44. Davison GM, Nkambule BB, Mkandla Z, Hon GM, Kengne AP, Erasmus RT, et al. Platelet, monocyte and neutrophil activation and glucose tolerance in South African Mixed Ancestry individuals. Sci Rep. 2017;7:40329.

45. Aukrust $P$, Müller F, Frøland SS. Circulating levels of RANTES in human immunodeficiency virus type 1 infection: effect of potent antiretroviral therapy. J Infect Dis. 1998;177(4):1091-6.

46. Davidson DC, Schifitto G, Maggirwar SB. Valproic acid inhibits the release of soluble CD40L induced by non-nucleoside reverse transcriptase inhibitors in human immunodeficiency virus infected individuals. PLoS One. 2013:8(3):e59950.

47. O'Brien MP, Hunt PW, Kitch DW, Klingman K, Stein JH, Funderburg NT, et al. A randomized placebo controlled trial of aspirin effects on immune activation in chronically human immunodeficiency virus-infected adults on virologically suppressive antiretroviral therapy. Open forum Infect Dis. 2017; 4(1):ofw278.

48. Nkambule BB, Davison GM, Ipp H. The evaluation of platelet function in HIV infected, asymptomatic treatment-naive individuals using flow cytometry. Thromb Res. 2015;135(6):1131-9.

49. Reeves BC, Deeks JJ, Higgins JPT, Shea B, Tugwell P, Wells GA. Chapter 24 including non-randomized studies on intervention effects. In: Higgins JPT, Thomas J, Chandler J, Cumpston M, Li T, Page MJ, Welch VA (editors). Cochrane Handbook for Systematic Reviews of Interventions version 6.1 (updated September 2020). Cochrane; 2020. Available from www.training. cochrane.org/handbook. Accessed 26 Sept 2020.

\section{Publisher's Note}

Springer Nature remains neutral with regard to jurisdictional claims in published maps and institutional affiliations.

\section{Ready to submit your research? Choose BMC and benefit from:}

- fast, convenient online submission

- thorough peer review by experienced researchers in your field

- rapid publication on acceptance

- support for research data, including large and complex data types

- gold Open Access which fosters wider collaboration and increased citations

- maximum visibility for your research: over $100 \mathrm{M}$ website views per year

At BMC, research is always in progress.

Learn more biomedcentral.com/submissions 